at 19 months of age. In each case the parents were healthy, and the mother was a multipara with the history of previous normal births. There was no history of prolonged or difficult labor, but in each case pituitary extract was administered early in labor, and birth was precipitate very shortly after. In each case, efforts at resuscitation were required and convulsions followed later; in two they continue to recur. Heard ${ }^{10}$ is convinced that these were cases of cercbral or meningeal hemorrhage and that pituitary extract was the etiologic factor in their production.

Obstetricians generally are coming to a realization that the child has a right to be born alive, and that the license to practice medicine cloes not also carry with it a license of executioner of the unborn child any more so than of the mother.

A COMPARISON OF STATISTICS OF 1914 AND 1916

Cases, 3,952.
Ruptured uterus, 8 cases, or 1
upture in every 494 cases.
letal deaths, 27 , or 1 fetal denth

1916 1916

Ruptured vterus, 12 coses, or ipture in every 106 cises.

lietal deaths, 34, or 1 fetal death in every 38 cases.

Asphyxia pallida, 1 case in every in every 146 cases.

Pituitary extract probably has a place in the obstetrician's armamentarium, but for its undoubted load effects on the child primarily, and on the mother in a lesser degree, it would seem that its field of usefulness is indeed a limited one. ${ }^{17}$

36. Heard, A. (i.: Texas State Jour. Med., 1916, 12, 264

17. In addition to the references alrendy given, the following will be of interest:

Bandler, S. W.: Med. Rec., New York, 1915, 87, 55, 166; Am. Jour. Olist., 1915, $\boldsymbol{\gamma}_{1}$. 674; Arch. Diagnosis, 1915, 8, 232.236; Med. Rec.

New York, 1915, 88, 607; New York Med. Jour., 1915, 102 882; An. Jour. Obst., 1916, 73, 77.92; Nexl. Rec., New York, 1116, 84, 300 .

Gall, P.: Gynäk.-Rundschau, 1914, 8, 394.

Trinks, O.: Prag. med. Wchnschr., 1914, 34, 347-349.

Jarrison, V. W.: Virginia Med. Semi.Month., 1914-1915, 19, 391

Rawlings, J.: Bull. El Paso Co. Med. Soc., 1914, 6, 9.18.

Kawlings, J.: Aull. El Paso Co. Med. Soc., 1914, 6, 9.18.

Sachs, E.: Monatschr. f. Geburtsh. U. Fynik., 1914, 40,

Gowell, H. L.: Ilinois Med. Jour., Surg., Gynec. and Oist., 1915, 20, 84.

Ebensen, K. A.: Ärch. mens, d'obst. et de gynce., Paris, 1914, 4, and $5,99.124$

Vogt, E.: Zischr. f. Geburtsl. 1. Gyniik., 1914-1915, 76, 746.762.

Fouche, It. P.: South African Med. Rec., 1915, 13. 20.

Kinnear, J. A.: Canad. Pract. and Rev., 1916, 41, 14.1.145.

Swezcy, A. J.: Jour. Iowa State Med. Soc., 1916, 6, 53.56

Quigley, J. K.: Pituitary Extract in Obstetrics, TIIE Jouknat A. M. A April 10, 1915, pp. 1222-1224.

Bell, J, F.: Internat. Jour. Surg., 1915, 28, 122

Norris, R. C.: $\Lambda \mathrm{m}$. Jour. Oisst., 1915, 71, 741.747

Elly, I. H.: III. Med. Jour., 1915, 27, 369-372.

liothergill, W. J: Jour Obst. and Gynec Brit. Emp, 1915, 27, 25

Hell, W. B.: I'roc. Roy. Soc. Ned., 1915, 8, Ohst. and Gign. Sect., pin. $71-77$.

Friedman, I. I. New York Med, Jour 1915, 102, 712

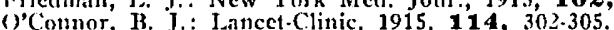

Mccirtney, J. il.: China Med. Jour, 1915, 29, 247,

(iallaglier and (iallagher: Surg., fiynec. and Olist., 1916, 22, 490.49.3

'elfair, J. II.: Am. Jour. Olist., 1916, 73, 655-662.

Cogburn, H. R.: New Orleans Med. and Surg. Jour., 1915-1916, 68, 738.742 .

King, R. W.: Northwest Med., 1916, 15, 125.128.

Joulkrad, C.: Therap. Gaz. 1916, 40, 305.307.

Valeus, J. A.: West. Med. News, 1916, 8, 128

Bell, W. 13.: Livernool Med.-Chir. Jouts., 1915, 35, 292.298.

Shefficld 1I. B.: Am. Jour. Obst., 1915, 60, 379.

Trapy: Monatschr. f. Gicburish. u. Gynike., 1915, 4, No. 36.

Production of Camphor.-As set fortlo in Commerce Reports, Alril 13, 1917, the estimated production of camphor in Japan for the ycar ending March 31, 1917, was 2,148,197 pounds, an increase of 35,121 pounds as compared with the actual production of 1915-1916. The estimated production in Formosa during this period amounted to $6,619,461$ pounds, an increase of 520,821 pounds, as compared with the actual yield of the preceding year. During 1916-1917, the estimated production of camplor oil in Japan was 4,237,852 pounds, an increase of 275,976 pounds as compared with the actual yield of 1915-1916. The estimated production of the oil in Formosa during the period named was $10,332,379$ pounds, or $1,249,153$ pounds in excess of the actual yield of 1915-1916.

\section{ONE ROAD TO THE CONTROL OF HEART DISEASE}

\author{
HENRY SEWALL, M.D. \\ DINVER
}

This note begins with analogy and ends in exhortation. The analogy consists in a fundamental likeness between the demographic aspects of what I will venture to call subclinical infections of the heart, and incipient tuberculosis of the lungs.

No broad scheme for the prophylaxis of tuberculosis was possible until hygienists grasped the fact that tuberculous infection is wellnigh universal. Thereupon the practical procedure became one largely of devising means to prevent a harmless anatomic infection from developing into a dangerous clinical disease. Accordingly, whatever the physical condition may be which the clinician is called on to consider, he has in mind tuberculosis. Particularly in the case of children does he search out in tuberculosis an explanation of morbid symptoms. The result is the control of established tuberculosis.

Just as civilized mankind harbors almost constantly a more or less latent tuberculosis, so infective disease of the heart, provoking no classical symptoms, but potential for catastrophe, is wellnigh invariable at some period of life. The practical conclusion from such a premise is that, as in the case of tuberculosis, the latent anatomic derangement may break down into functional inefficiency in an unfavorable environment, such as added infection or overuse.

The proof of such a proposition can be established only after years of definite research; but sufficient evidence is at hand to justify the clinician in accepting it as a working hypothesis. As has been slowly apprehended in the case of tuberculosis, only on the assumption of the universality of cardiac infection will the clinician give adequate consideration to morbid signs which point to cardiac disease.

From the point of view of the public health officer, Darlington ${ }^{1}$ has given statistical evidence that the mortality rate from heart disease is positively increasing throughout the United States, while the general death rate is steadily decreasing.

The fundamental basis on which must rest a belief in my thesis is the incompleteness of the evidence offered by physical signs of the organic conclition of the heart. From the point of view of the pathologic anatomist, Warthin ${ }^{2}$ has shown how doubtful is the ultimate cure of any infectious disease and, particularly in the case of syphilis of the heart, that profound organic infection may exist without appreciable clinical signs.

Necropsy records, including careful histologic and cultural examinations of the cardiac tissues, must furnish the crucial evidence as to the dissemination of heart lesions, and none can dispute the urgent duty of the pathologist to provide appropriate records. On the clinician, however, devolves the task of determining the functional capacity of the heart during life, and the practical application of methods to restore power and prevent failure.

We are not here concerned with the obvious cardiac lesions which are causing or threatening broken compensation, but only with what may be called "sneaking heart disease" in which the classical signs of insuffi-

1. Darlington, Thomas: Tr. Am. Clin. Assn., 1908, 24, 120 20, 416 . 
ciency are absent but in which there is a clangerous narrowing of what James Mackenzic calls the field of physiologic response.

It must be granted that the clinical data of physical diagnosis are absurdly insufficient to supply a reliable fund of information. While medical students are taught the words which signify that the pathologic importance of a heart lesion depends on involvement of the heart muscle rather than on changes in its lining membrane, the statement may be boldly ventured that the endocardial murmur is still the sole language through which the heart can speak its limitations to the casual examiner.

It is doubtful if the student keeps clearly in mind that even valve lesions are probably all due to infecetions conveyed not by the intracardiac flood which bathes the valves but by the capillary streams which spring from the coronary circuit, and that the slightest attack on a valve presupposes a more or less widespread infection of the myocardium. (irinting a locus of infection within the heart, the teachings of the new science of immunology must leat us to suspect that at once the vital reactions of cardiac protoplasm hecome profoundly modified. Feven the crude linowledge in our possession today points indubitably to the conclusion that heart fissue so attacked becomes, as it is said, "sensitized" to the particular form of poison with which it is inoculated, and thereafter abnormally receptive of new accessinus of the same poison, and susceptible to them. The clinical facts that support this point of view are simply numberless. Fortunately for the prescrvation of the higher forms of life, protoplasm attaclied by a foreign poison, after an initial stage of heightened susceptibility, is apt to acquire a specifically strengthened resistance to the noxa. But this "immunity" is always merely relative, and it were vain in a given case to estimate in advance the ratio of virulence to resistance.

The canny practitioner of medicine wiscly takes his generalizations only as inductions from individual experience. Nothing, in my opinion, conld be nore fruitful for good than for the student of disease to estimate "the ficld of physiologic responsc" in the hearts of his paticnts, according to the views set forth.

\section{EXAMPLES OF LATENT HEART DISEASE}

A few concrete clinical examples of a familiar kind may make clearer the source of the impulse that led to this article:

$C_{\text {ASE }} 1 .-\Lambda$ man of fine physique, somewhat under 40 years of age, developed articular rheumatism. Nothing wrong hacl previously been found with his heart, but now there was detected obscurcly at the apex a murmur of that peculiat quality which one learns to associate with fresh chlocardiel lesions. Uncler some medication and prolonged rest the physical powers secmed to become completely restored aurl the murnur, changed in quality, had nearly disappeired.

Many months later the patient was acceted for life insurance by a conscientious and competent examiner who, though informed of the history, could detect no cardiac lesion whatever. Since then, a number of times in the course of several years, the patient has applied for treatment of a sore throat, and on each occasion a slight hruit could be detected at the apex, the abnormal sound becoming temporarily a distinit murmur during a recent acute rlicumatic attack involving throat and muscles.

$\mathrm{My}$ conclusion has been that this active business man carries a chronic infection of the heart which seinsitizes the organ toward rheumatic toxinis. It is impossible, of course, to pronounce whether the new endocardial nurmur accompanying each attack of sore throat was the mechanical result of an altered circulation or a sign of fresh infective turgidity of the mitral valve. One who watches the quality changes in such a murnuur clay by day is apt to incline to the latter explanation.

Of the numerous tests to determine the functional efficiency of the heart, nearly all fall within the limbo of "academic" procedure. It is usually doubtful whether a functional inefficiency thus determined shows pathologic impairment or only lack of physical training or weakness of other coordinated organs.

CAsl: $2 .-\Lambda$ man, aged about 25 , of powerful physique, who had a perfectly compensated mitral lesion for some years and who was apparently in excellent health and strength, entered a inilitary camp and was set to digging a trencl.

$A$ physical cxamination disclosed too late his unfitness for the task. A prolonged and fatal illness followed, bearing all the features of an infective cardiac disorder.

While the following explanation of this casualty cannot be proved, it hammonizes many facts and suggests a safe working hypothesis: In the foregoing subject, infection and resistance within the heart had been so balaneed that functional processes reniained normal. Whon excessive physical strain was put on the anatomically defective organ, its mechanical imperfection led to a "break in compensation," that is, the left ventricle ceaserl to deliver blood as fast as it was received by the right atricle. $\Lambda t$ once disturbance of cardiac nutrition was instituted. Immediately the biologic "resistance" of the heart tissues deteriorated, and the infective forces, which had been held in subjection, began to talie on strength and to propagate their lind.

$\Lambda$ tissue which is the scat of a viable infection is like a seesaw; on one end is scated physiologic resistance, on the other infective virtulence; the balance represents the ratio of the two forces. Precisely in the same way we frequently find that a quiescent pulmonary tuberculosis is lighted up into progressive disease by injudicions habits. Indeed, the salutary relation of rest in active tuberculosis is identical, with greatly increased cmphasis, in acutc heart discase. In tubcrculosis, Nature is prone to forgive the careless transgressor; in heart discase, perhaps more rarely.

CASE 3.-A strong youth had a slight inclisposition whici was evirlently theumatic, but he was not so ill as to refrain from ricling several miles on his bicycle to an entertainment. The return jottrney was made against a strong wind. The hoy was obliged to scek his bed on reaching home, and soon feveloped signs of a gencral cardiac inflammation that carried him off.

I insist that these cases do not find their complete cxplanation in mechanical overstrain of the heart, but inclicate an intense intoxication, such as the immunologist is prone to denlonstrate in his reactions of anaphylaxis. Moderate overstrain of a normal organ is probably an indifferent episode, but the same test applied to an infected organ sets in play chemical reactions which lead to physiologic destruction.

An aderpuate study of heart discase will disclose another line of contact with pulmonary tuberculosis. In the latter disorder, accunulating clinical experience points more and more frequently to the period of early youth as the time of primary infection. In the same way the student of breaking cardiac compensation can often trace the history through a long period of latent disease to a definite moment in early life when some 
Herpes zoster may develop in any phase of paresis, ${ }^{\circ}$ often coming at the onset before the appearance of the characteristic symptoms. It may develop in the course of the lightning pains of tabes. ${ }^{10}$ In tabes and paresis, herpes zoster is incidental to an involvement of the ganglions and roots in the pathologic processes of these discases, ${ }^{11}$ although it must not be overlooked that the diseased condition of the nervous system may open the portal for the specific form. It is interesting to note, incidentally, that Knowles ${ }^{12}$ mentions the occurrence of herpes zoster together with a maculopapular syphiloderm, and also the occurrence of herpes zoster in a patient with gummas.

Zoster involving the entire length of the upper cxtremity alone (as in the first case report) appears to be uncommon. Knowles ${ }^{12}$ observed four cases of zoster involving the entire length of the upper extremity out of 273 cases of herpes zoster in which the distribution was mentioned. ${ }^{13}$

\section{REPORT OF CASES}

CASE 1.-M. K., aged 50, lalorer, was an advanced paretic admitted to the Philadelphia Hospital for the Insanc, Fel. 10, 1915. Oct. 25, 1915, there was an eruption confined to the right upper extremity as follows: Starting above the axilla the eruption ran along the posterior margin of the deltoid muscle; it occupied an area corresponding to the lower half of the body of the deltoid; below this the outer (lateral) portion of the upper arm, including the outer portion of the flexure of the elbow, and the outer aspect of the forearm, both anteriorly and posteriorly. There were a few vesicles on the dorsum of the hand, slightly beyond the wrist, in line with the metacarpal bone of the index finger; there were a few vesicles toward the palmar aspect of the hand, and along the metacarpal hone of the thumb, extending to the base of the nail. The distribution ${ }^{\text {ts }}$ of the eruption corresponded to the fifth, sixth, seventh and eighth cervical nerve roots (according to the nomenclature of Bärensprung, a cervicobrachial zoster). The vesicles were in groups, on a reddlened base; some werc filled with hemorrlagic serum. In some places they were broken down with ulceration. The patient had not received arsenic, iodids or any other medication; he had not been injured. There was no evidence of any acttal paralysis, or any alteration of the reflexes from the previous condition. The patient did not seem to suffer any pain; this may have been due to his

9. IÍ́rissey, Paul: Ptudes cliniques sur les troubles trophique dans la piralysie générale, Paris thesis, 1903. De Fursac and Rosanoff: Manual of Psychiatry.

10. Osler: Practice of Medicine.

11. Poincaré and Bonnet (Ann. méd.-psych., 1868 and 1876) first described structural and functional alterations of the sympathetic ganglions in paresis, and Klippel (1892) first described the peculiar microscopic visceral lesions which he attributed to ganglionic changes (Martial Vignaud, Historique de la paralysie génćral, Paris thesis, 1902). These chronic degenerative changes in the ganglions, which are distinct from the acte changes in paresis causing herpes zoster, may be from the acte changes in parcsis causing herpes zoster, may he (retrograde degencration).

12. Knowles, 1\%. C.: Herpes Zoster, Report of Two Hundred and Eighty-Six Cases, with a keview of the Unusual Features of the Disease, Penusylvania Med. Jour., 1911-1912, 15, 615.622.

13. Other cases, to which I have had access, are: Stopin, Le zona du membre supérieur, Paris thesis, 1882-1883. The entire length of the tipper extremity was involved in six instances out of seventeen cases of herpes zoster of the upper extremity. Gordon, Alf red: Cervico. Brachial Herpes Zoster, Am. Med., 1909, N. S., 4, 627-630. Carpenter, G.: A Case of Herpes Zoster Extending to the Finger Tins, Rep. Sc. G.: A Case of Herpes Zoster Extending to the Finger Tins, Rep. Sc. Study of Diseases of Children, London, 1905, 5, 3. Pfeiffer (quoted
by Blascbko) quotes one case (Jootnote 4). In larger series of herpes by Blascbko) guotes one case (Jootnote 4). In larger series of herpes zoster reported (Hoennicke, Cantrcll
of the eruption is not mentioned.

14. In determining the level involved, one must take into account the following factors: 1. A given area, though usually supplied by a given root, may instend be supplied by the root above, with corresponding clinges in the other roots, or by the root below, with corresponding changes in the other roots. 2. In a very large proportion of cases the eruption does not occupy the whole area of a single nerve root. 3. The shape of the part involved (whether thin, stout, eic.) makes a difference in the appenrance of the cruption. 4. There is a certain amount of overlapping of supply in a given segment by the one certain amount of overlapping of supply in a given segment by the one
above and below. In outlining the area of involvement one includes the zone of hyperemia as well as the eruption proper. Cases in which only a single segment is involved are of value in determining the area stipplied by a given nerve root. In any one case one cannot be abs lutely certain which root is involved unless confirmed by necropsy. advanced dementia. The teeth and the tonsils appeared to be normal.

A spinal puncture was done, October 28 . The fluid was under much increased pressure (spurted). The Wassermann reaction was positive, culture negative. The Wassermann reaction in the blood, taken the same day, was positive. The patient's temperature was normal throughout the course of the eruption. A white cell count, November 1, revealed: leukocytes, 6,900 ; neutrophils, 64 per cent.; lymplocytes, 34 per cent.; mononuclears, 1 per cent.; cosinophils, 1 per cent. The patient also had psoriasis, which was present on admission.

The cruption had healed (with a few scars) at the time of the patient's death, which occurred, Nov. 23, 1915.

Owing to an oversight, the spinal cord was not removed at necropsy. Histologic examination ${ }^{13}$ of the brain confirmed the diagnosis of paresis. The upper ervical cord showed marked involvement of both the tracts of Goll and Burdach.

CASE 2.-T. M., man, aged 49, vagrant, was admitted to the wards of the Philadelphia Hospital for the Insane, Oct. 26,1915 . The patient was a paretic with some tabetic symptoms. The eye grounds were normal. The Wassermann reaction was positive in both blood and spinal fluid. Several teeth were represented by old decayed roots.

November 5 , a redness was noticed on the right side of the forchead. The next day vesicles appeared.

November 6 , the border of the eruption started at the hair line laterally and went across to the root of the nose, including the upper lid; the conjunctiva was reddened. There were a few vesicles on the bridge of the nose. The horder of the rash then extended up the midline; the upper border was slightly beyond the hair line of the forehead.

November 8 , the eruption became infected.

November 9, the patient's temperature was $100 \mathrm{~F}$. It was normal the next day.

November 18, the eruption was practically healed, with rather extensive scarring. The hair line of the cyebrow was involved in a scar with some loss of hair. The patient complained for a time of slight hyperesthesia in the region involved. The sense of pain in this area was considerably diminished; the touch and temperature senses were normal.

The following report on the spinal fluid was submitted by Dr. Kolmer: Clear; total cells, 30 per cubic millimeter, all small lymphocytes; protein reaction positive: Noguchi, +; Pandy, + ; Nonne, + ; Kaplan, ++ ; sugar, normal; colloidal gold, 5555544311 (paretic curve); Wassermann reaction (dose 0.8 c.c.), strongly positive; cholesterinized antigen, ++++ ; alcoholic syplilitic liver, ++++ ; acetone insoluble lipoids, ++++

The patient's tecth sulsequently became loose. Dementia and physical signs increased. He died, July 23, 1916, in a congestive attack, associated with restlessness and stupor; there were no convulsions or paralyses. Aside from atheroma of the aorta, and chronic myocardial and renal changes, the general organs showed nothing of note. Grossly the brain showed the following lesions of general paralysis: (1) chronic hemorrhagic pachymeningitis; (2) chronic leptomeningitis of the superior and anterior portions of the cerebrum, and (3) granular ependymitis of the floor of the fourth ventricle. There was no apparent cerebral atrophy. Histologic examination confirmed the diagnosis of paresis. The perivascular infiltration was unusually severe in the occipital pole. Gliosis was fairly marked in the column of Goll. The gasserian ganglion and its roots showed fibrosis and also round cell infiltration. The picture was one of chronic and also acute changes, the latter being of a nonseptic type, and probably specific (syphilitic)

CASE 3.-P. H., aged 51, admitted to the wards of the Philadelphia Hospital for the Insane, June 21, 1915. Blindness commenced five years before, and mental symptoms two months before admission. The eyes showed nystagmus; the pupils were equal, slightly irregular and inactive. There was complete optic atrophy of the eye grounds, probably primary. The knee jerks were absent. Romberg's'sign was present when the eyelids were closed; there was ataxia in the lower extremities; there had been slight difficulty in holding the urinc

15. I am indelsted to Dr. Samuel $T$. Orton for the histologic studies. 
during the last six months; the teeth and the tonsils were normal. The patient had a psychosis, but was not a paretic. Tabes dorsalis was diagnosed; a positive mental diagnosis was not made." Dr. Kolmer submitted the following report on the spinal fluid, June 14, 1916: Clear, 90 cells per culjic millimeter; 92 per cent. small lymphocytes; protein reactions strongly positive: Noguchi, $+++;$ Nonne, Plase $\mathrm{I},+++$ glucose content, normal. Wassermann reaction (dose 0.8 c.c.), ++++ , with the three antigens used above; Lange colloidal gold test: typical paretic curve. ${ }^{17}$

June 6 , there was redness on the right side of the forehead. June 8 , vesicles were well marked. The outer border of the rash extenderl upward from the outer end of the eyebrow; the inner border was at the midline. The rash included the upper lid, and the nose to the ala; the conjunctiva was reddened, but contained no vesicles. The rash extended backward to slightly beyond the parietal eminence. The blood count was normal. There was a slight rise of temperature a few days later due to sccondary infection. June 21 , the eruption had well disappeared, except for scabs along the eyebrow.

At present, on the forehead, upper lid and the bridge of the nose, the areas which were formerly the bases of the vesicles show loss of pigment. Neither in these whitish areas nor in the normal appearing skin can any disturbances of sensation be demonstrated.

\section{CONCLUSIONS}

Of three patients having an attack of herpes zoster, two were paretics and one a tabetic. The cases of herpes zoster were of the symptomatic variety, that is, due to involvement of the ganglions in the pathologic processes of the disease from which the patients werc suffering. The nature of the ganglionic changes is in atl probability specific, that is, due to spirochetes or toxins.

Thirty-Fourth and Pine Streets.

16. The patien's mental condition may have been dependent on syphilitic changes or alcoholism. On admission, dementia, though present, was not very apparent; it has since progressed, but is not extreme. There is nothing, lowever, in the clinical symptoms, which

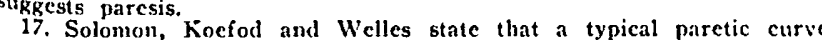
may occur not only in patients wloo do not have paresis, but also in patients who do not even have syphilis. I have seen two nonparetic with typical paretic curycs. In one of these at least, the question of Baresis sinc paresi does not enter (Solomon, H. C.; Koefod, H. O. an Welles, E. S.: Dingnostic Value of Lange's Gold Sol Test, Boston 'Med. and Surg. Jour. 1915, 173, 956-960. Solomon, H. C., and Welles E. S.: Varieties, of the (iold, Sol Test (Lange) in Several Loci of the Cerebrospinal liuid System, ibid., 1915, 172, 625.629). A paretic curve is reported in a child suffering from poliomyelitis, with a positive Wassermann in in a child sufering rom poliomyelitis, with a positive The Collann in the spinal find myelitis. Tit Jold Reaction of the Cercbrospinal 1uid in Acute Poitiovations, THE JOURNAl. $A$. M. $A$., March 10, 1917, D, 752). These obser other show that the paretic curve occurs occasionally in condition the patient described above is not a paretic.

Milk Distribution a Public Utility.-A joint commission of Pennsylvania, Maryland and Delaware appointed to study the milk question with reference to price, distribution, etc., headed by Prof. Clyde L. King of the University of Pennsylvania, recommends (Strvey, Fel)ruary 24 ), that milk distribution shall be recognized as a public utility. The recommendations cxtend to both production and distribution, and include suggestions for increased state and municipal supervision, as well as an attempt to harmonize the interests of producers, dealers and consumers. Recognition of milk distribution as a public utility implies the keeping of accounts by dairymen and dealers in a form prescribed by the state, the state examination of accounts, the licensing of all dealers, as at present; the licensing of testers in receiving stations, and the standardization of prices. Seasonal inequality of production has been an obstacle to the maintenance of uniform price to producers, which makes the financial success of the dairy business uncertain. This, it is suggested, can be overcome to some extent by the storage of milk in the form of butter, cheese and condensed milk, and the stimulation of new uses at times of greatest yield. The competition of milk with other food products and the matter of freight rates complicate the milk supply problem.

\section{A CASE OF BROWN-SÉQUARD PARALYSIS *}

\author{
LEWIS J. POLLOCK, M.D.
}

Instructor in Nervous and Mental Disease, Northwestern University Medical School

CHICAGO

Until recently, many workers, following BrownSéquard, held that impressions of pain and temperature pass upward through the gray matter, while those of touch and sense of position ascend through the dorsal columns. Petrén, ${ }^{1}$ from a collection of reports of a large number of cases, concluded that impressions of pain and temperature pass through the opposite lateral column, and of the muscle sense through the homolateral dorsal column, while two paths are open to touch, one through the uncrossed exogenous fibers of the dorsal column, and another in the opposite lateral column.

Head and Thompson ${ }^{2}$ confirmed these conclusions and showed that the ability to recognize the simultaneous contact of two compass points depends on impulses traveling through the homolateral dorsal column. Head and Holmes ${ }^{3}$ found that the appreciation of weight and recognition of size and shape are frequently lost on the paralyzed side, and concluded that the impulses which subserve these functions ascend uncrossed through the dorsal columns. Egger ${ }^{4}$ has slown that the sense of vibration of a tuning fork depends on the integrity of the dorsal columns.

Recently Petrén," from a review of ninety-four cases of stab wounds of the spinal cord, has concluded that fibers for pain and temperature sense have their course near the lateral column of the cord. For touch two pathways are present: first, in the posterior columms in the long exogenous fibers and, second, in the crossed lateral columns somewhere along with pain and the temperature sense. The fibers for muscle sense do not run in a crossed tract; they run in two columns, one in the homolateral posterior columns and the other in the lateral cerebellar bundle. They run mediad to the fibers for pain and temperature and laterad to the pyramidal tract.

From the notes of forty-five cases of spinal injuries of warfare in which the Brown-Séquard syndrome occurred, Holmes ${ }^{\mathfrak{d}}$ found that the upper limit of anesthesia to the different forms of sensation varied, and that as a rule the upper border of the contralateral loss did not correspond to the segmental level of the injury. In the middorsal region, the crossing of pain and thermal impulses is complete in one segment. Thermal impressions cross less rapitly than those of pain, and touch requires two segments for decussation. In the upper dorsal segments, pain and temperature cross in two and frequently in three segments. At the fourth cervical segment the decussation of pain requires from five to six segments, and that of thernal impressions from four to five.

Holmes concludes that the fibers which convey impression from the lower spinal roots are probably placed lateral to those which have later reached the contralateral side.

- Read before the Chicago Neurological Society, Dec. 21, 1916

1. Petrén: Skantin. Archiv. f. Physiol. 1902, 13,9.

2. Head and Thompson: Brain, 1906, 28, 537

3. Head and Holmes: Brain, 1911, 34, 102.

4. Egger: Rev. neurol., 1902, 10, 549.

5. Petrén: Neurol. Centralbl., Jan. 2, 1916.

6. Holmes: Brit. Med. Jour., Dec. 11, 1915, p. 855 